\title{
ASSESSING THE IMPACT OF ACCOMMODATIONS ON MoOd ANd Future Travel ACtions During A SHORT-TERM STUDY ABROAD EXPERIENCE
}

\author{
James Tanoos \\ Purdue Polytechnic Vincennes, USA
}

\begin{abstract}
The global tourism and hospitality management industry has been expanding for decades, interrupted only by post-9/11 shutdowns and the 2020 coronavirus pandemic. The literature in this field has evolved over the past several decades toward more nuanced travel research related to travelers' moods and how to keep them happy throughout their trips, and governments today are spending more than ever to market their locales to potential visitors, in order to better facilitate local tourism and increase intra-trip spending in order to secure tax dollars in their budgets. Consumer behavior literature on tourism has focused on the various on-site experiences of travelers in the past. This study will assess student attitudes toward different types of hotels during a recent study abroad, and the impact of these reactions on the likelihood of spending during the trip as well as the likelihood of repeat visits to those locations in the future.
\end{abstract}

\section{KEYWORDS}

Short-term study abroad, tourism, hotel accommodations, travel pedagogy

\section{INTRODUCTION}

The global tourism and hospitality management industry has been expanding for decades, interrupted only by post-9/11 shutdowns and the 2020corona virus pandemic. The literature in this field has evolved over the past several decades toward more nuanced travel research related totravelers' moods and how to keep them happy throughout their trips, with the goal of increasing intra-trip spending and/or increasing the likelihood that they will take another trip to the location in the future.

Today, governments are spending more than ever to market their localesto potential visitors, better facilitate local tourism and increase intra-trip spending in order to secure tax dollars in their budgets. The consumer behavior literature on tourism has focused on the various on-site experiences oftravelers. Following this line of research, this study will assess travelers' attitudes toward different types of hotels and the impact of these reactions on the likelihood of spending during the trip as well as the likelihood of repeat visits to those locations in the future.

\section{Literature REVIEW}

While the recent world pandemic will certainly spawn an abundance of literature discussing its negative impact on the tourism industry in 2020 and beyond, research dedicated to the field of global tourism and hospitality management has been active for several generations. 
Cohen (1985), a pioneer in travel research, provided a seminal analysis of "tourist guides", who have a significant tradition ofhosting travelers in major international cities (Wynn, 2011) and play an influential role in motivating and managing visitors' experience in the local culture (Weiler \& Davis, 1993). With increased global travel patterns in recent decades up until the recent pandemic, many countries have increasingly benefited from private tour guides to best promote the activities and sites in their communities (Matias et al., 2011; Mason, 2015).

The global hospitality sector provided wages for 313 million jobs worldwide in 2017 (Kendall College, 2018), and 253 American colleges now offer hospitality management majors (College Factual, 2020). The number of positions in the travel industry nearly tripled from 2009 to 2018 (Deloitte, 2019) and 2018 was the $8^{\text {th }}$ consecutive year of tourism growth, with 1.4 billion annual travelers (World Tourism Organization, 2020). Competition between private tour agencies has risen to such a point that ratings of tour agencies and tour guides have attracted attention not only in the literature but also in popular ratings websites like Travelocity and various forms of social media.

Unlike in the past, tourism has become a central component of many economies, as cities around the world are proactively marketing their locations for potential tourism revenue (Tribe, 2011; Vanhove, 2011; Matias et al., 2016; Kozak \& Kozak, 2015; Meng \& Siriwardana, 2016).By 2018 , the tourism industry accounted for $3.2 \%$ of the global economy and was an integral component of many countries' economies (WTTC, 2018). Truly, travel facilitators in cities and countries today attempt to market their locations as best they can in order to enhance the benefits of tourism spending to their economies. Tribe (2011) described one government's strategy to "harness the tourism industry to spearhead economic development" (p. 322), promoting the locale to travelers in order to reap the benefits of their spending in order to avoid increasing local taxes. By 2018, 12 countries around the world had 15\% or more of their national GNP dedicated to their global tourism and hospitality industries (Smith, 2018).

With an increased amount of revenue to local economies being attributed to tourism, the stakes have been raised. The literature on hospitality management has now gone beyond studies related to tour guides and economic impact to assessing how consumer experiences shape consumer moods. As such, a growing trend is the focus on how the traveler's moods prompt related consumer behaviors (Chang and Gibson, 2011; Tsai, 2010; Voigt et al., 2010). There are numerous studies on which psychological and consumer behavior factors during travel prompt travelers to buy and behave certain ways (Ladhari, 2007; Bosque and Martin, 2008; Chang, 2008; Slatten and Mehmetoglu, 2009). Man-U lo (2017, p. 151) surmised that "Positive emotions play an important role in tourists' satisfaction and behavioral intention". Mitas et al. (2012) found that the travel industry is most impacted by travelers' emotions, and Man-U lo (2017) stated that "positive emotions were evidenced for their significant impacts on tourists' satisfaction" (p. 153).The ability to gauge and tap-in to a traveler's emotions during a trip is advantageous for the hospitality management and global tourism industries to continue to reapeconomic benefits.

Tourism experiences and their effect on psychology and emotions can dictate future consumer behavior behaviors such as the selection of accommodations. Mitas et al. (2012a) pointed out that the emotions of travelers are the most relevant variable affecting the entire tourist industry. "The understanding of how tourism experiences shape tourists' positive emotions is crucial" (Man-U Io, p. 152, 2017), and the ability to facilitate positive experiences for travelers is becoming an important facet of the tourist industry in order to best facilitate repeat travelers to their locales. Precise management of the travelers' emotional process isimportant in order to predict their buying patterns on the trip and importantly, the likelihood of future travel. 
Some researchers have investigated the timeframe during a trip in which the traveler is most and least happy. Nawijn et al. (2012) found that "Vacationers on an 8- to 13-day trip feel best during the middle of their trip and worst at the end" (p. 272). Pearce (1981) found that the beginning of a trip is where a traveler is more likely to experience negative reactions such as health issues and culture shock. The configuration of accommodations to best meet the intra-trip mood of travelers is becoming increasingly important for travel agencies to ensure happy travelers and positive consumer behavior patterns.

While it is difficult to quantify the happiness of a traveler, it has been found that generally, the positive emotions of tourists are shaped by their experiences on-site, whether that be a hotel, transportation, events, excursions, and so forth (Man-U, Mitas et al., 2012a; Su and Hsu, 2013b). In particular, hotels are an integral component of the tourism industry and have been studied to assess their impact on travel experiences and the local economy (Singh et al., 2006; Jones \& Chen, 2011; Chang, 2014; Becker, 2016; Gao \& Mattila, 2016; Wood, 2017; Mauer \& Siller, 2019).The global hotel industry uses a star ratings system in order to facilitate target marketing, so that travelers more easily understand the costs associated with various styles of hotels. Even though travelers are utilizing the accommodation option of Airbnb'smore often, the hotel industry remains at the heart of the tourism industry.

The planning and execution of travel arrangements is not just the realmof travel agencies and governments. Study Abroad (SA) programs from institutions of higher education have learned and benefited from general tourism and hospitality management pedagogy. Specifically, the increasing popularity of short-term SAs (those lasting 3 weeks or less) tends to mirror the timeframes of vacationers and other global travelers. Short-term SAs have been more commonly offered in recent decades in order to increase the likelihood that students will be able to take part in a trip. Barkley and Barkley (2013) reported that cultural encounters are an important ingredient of a short-term SA if administered appropriately, and scholars have pointed out that if a short-term SA is planned and coordinated appropriately, true cultural awareness and insight can be adequately gained (Chieffo and Griffiths, 2004; Martinsen, 2011; Vande Berg et al., 2012).

During these planning stages, decisions about sitesare structured and coordinated well in advance, including transportation, hotels, and excursions. Teichler and Steube (1991) found that the planned logistics of a SA trip will make or break students' experiences.

While there have been numerous studies describing the mood-assessment of travelers, the best way to structure a SA, and hotel accommodations target marketing, there have been no studies on student consumer behavior reactions while on a SA and how their experiences in local hotels affect their mood as tourists and/or future tourists.

\section{Methodology}

A predictive study is a type of experimental design which is utilized to ascertain when and in what situations an event will occur. In this case, the goal was to discover the effects of differently rated hotels on student attitudes. This study will attempt to test for a relational hypothesis or a causal hypothesis about how accommodations at hotels prompt specific reactions and/or intentions.

This study assessed the attitudes of 18undergraduate students from a public higher education institution in the American Midwest (which is a member of the Association of American Colleges \& Universities) during a 3-credit SA trip that took place over the course of 14 days in May2019. All the students were majoring in a technology-related field. This trip covered four cities in three Central European countries, all of which were listed among the top 32 European 
cities for millennials to live in (Bloom, 2017).Students stayed in a hotel for three nights in each of the cities. One hotel had a 4-star rating (Munich), two hotels had a 3-star rating (Rotterdam and Hamburg), and one hotel had a 2-star rating (Prague).

Surveys were distributed (see appendix B) immediately after the stay in each hotelin order to determine how the hotel affected the students' attitudes in an array of areas and so that their cognitive reactions would be assessed in relation to how they affect other variables. Survey questions were developed in light of the Man-U lo (2017) study stating that "positive emotions were evidenced for their significant impacts on tourists' satisfaction" (p. 153).Seven questions were included on a Likert-type scalein order to assess the hotels' impact on student mood(see appendix B).

\section{Results \& Future Studies}

Answers to the questions were coded from -2 (worst) to +2 (best), with zero as a mean for all questions. One student filled out the forms incorrectly and was dropped from the sample set. The Kolmogorov-Smirnov Test was utilized because it compares two distributions to assess if they show any significant difference. For each test, a D-value (test statistic) is obtained, along with a $p$-value; if the $p$-value is significantly low (often said to be less than 0.05 ), it can be stated that the distributions appear to be significant. The first eight of these tests are intended to assess whether the rate or responses to the seven questions have a normal (bell-shaped) curve. This analysis found that none of these distributions was normally distributed.

Table 1.Test Statistics for Responses to Seven Questions

$\begin{array}{lll}\text { Treatment } & \text { D Value } & \text { p-value } \\ \text { Q1 } & 0.97725 & <0.05 \\ \text { Q2 } & 0.96162 & <0.05 \\ \text { Q3 } & 0.84134 & <0.05 \\ \text { Q4 } & 0.86787 & <0.05 \\ \text { Q5 } & 0.84134 & <0.05 \\ \text { Q6 } & 0.85225 & <0.05 \\ \text { Q7 } & 0.97725 & <0.05 \\ \text { Rate } & 0.96162 & <0.05\end{array}$

The next test compares the relationships between pairs of distributions for pairs of questions. A $p$-value equal to 1 is indicative of responses to both questions being the same. The following pairs of questions showed differing distributions, or opposite responses to the questions: Q4 and Q5, and Q5 and Q6, which makes sense because those asked opposite questions pertaining to money. Paired questions with extreme values are included below.

Table 2.Comparison of Student Responses to Paired Questions

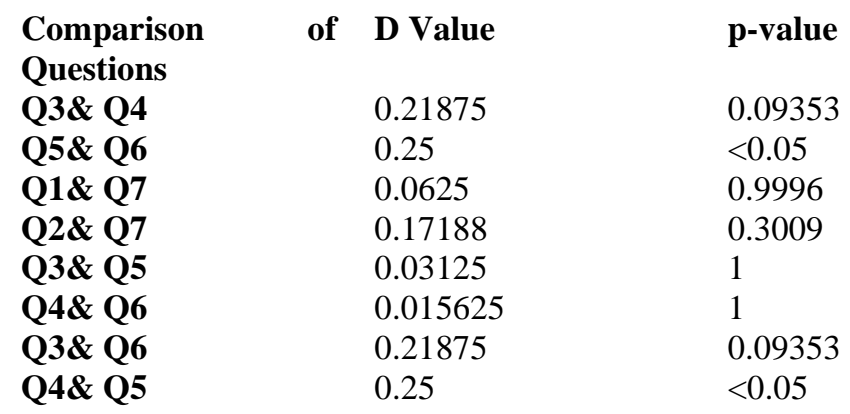


As seen in the table above, Q7, the question involving the effect of the hotel accommodations on the student's "mood" was paired most specifically with Q1, or the question about the likelihood of coming back to a city again in the future. Q2 (analyzing the effect of living in the city in the future) showed a very high central value of the accommodations not affecting a desire to live in the city. In fact, for $56 \%$ of students, the accommodations did not affect their desire to live in the city. However, Q1, which simply asked about visiting the city again (as a guest or tourist), showed a slight bimodal distribution, with some students picking no effect and some picking much more likely. Below is a visual representation of these responses.

Figure 1.Student Responses to Seven Questions, by Percentage

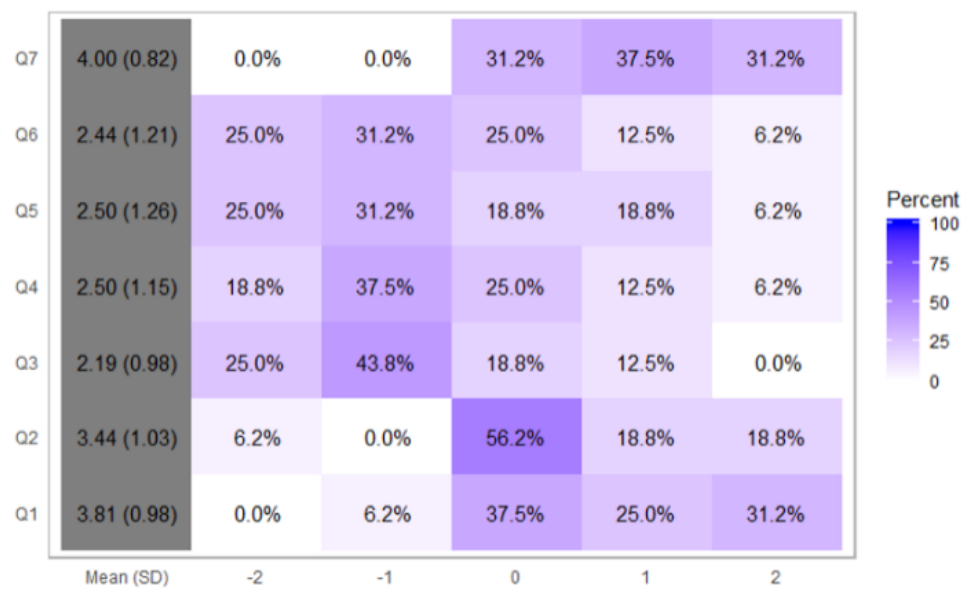

Figure 2.Student Responses to Seven Questions, by Mean

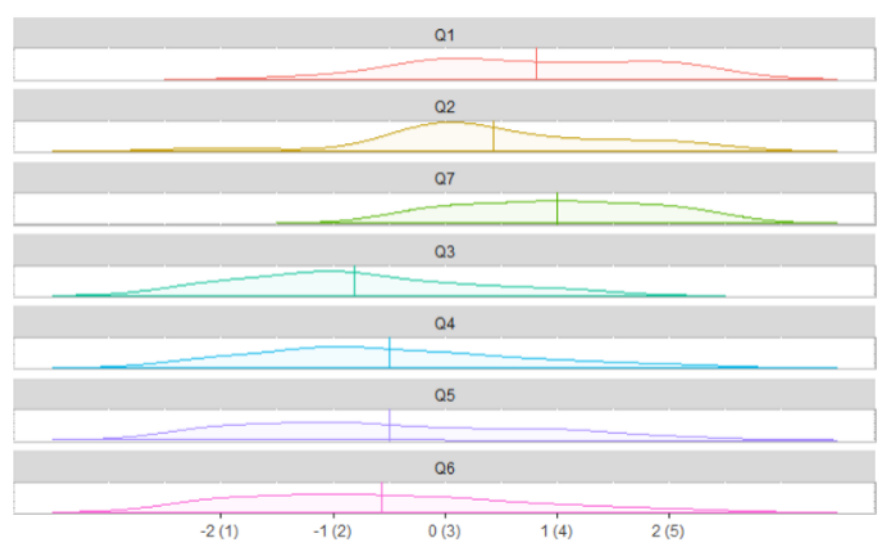

The figure below depicts the difference in percentage of students based on score levels for Q1 across each of the four different hotels. The graph shows that across different hotels, the percentage of students who provided ratings at each score level is approximately the same, when this figure compared to the figure below it with responses to Q7. 
Figure 3. Student Responses to Question 1, "How much did the accommodations affect your likelihood of coming to the city again?"

Q1 for four hotels

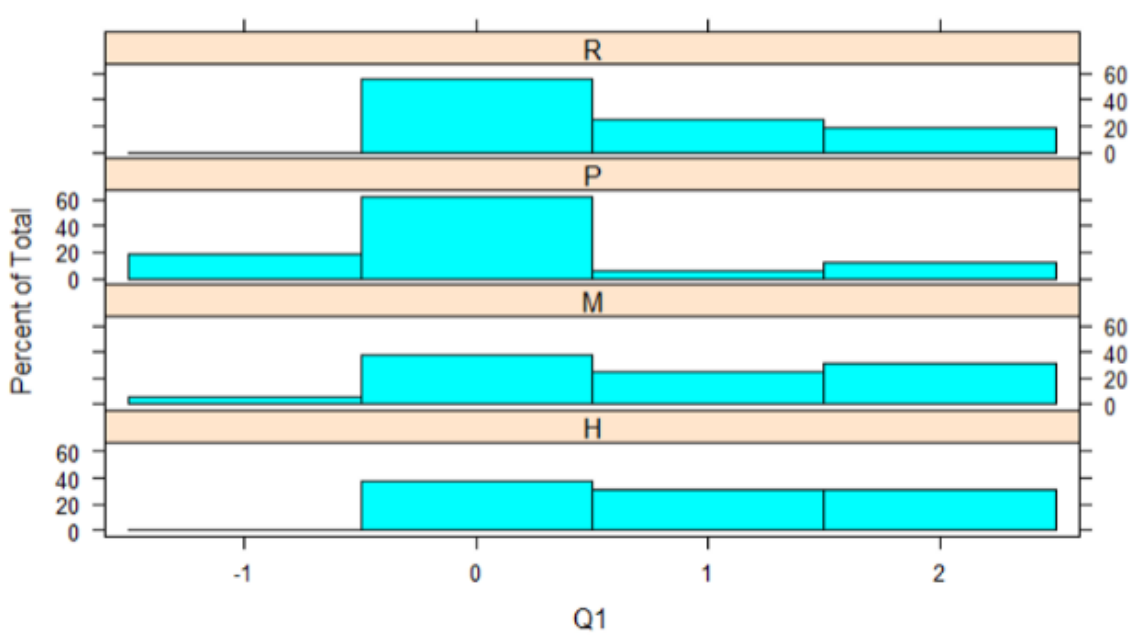

Figure 4. Student Responses to Question 7, "How did the accommodations affect your mood in this city?"

\section{Q7 for four hotels}

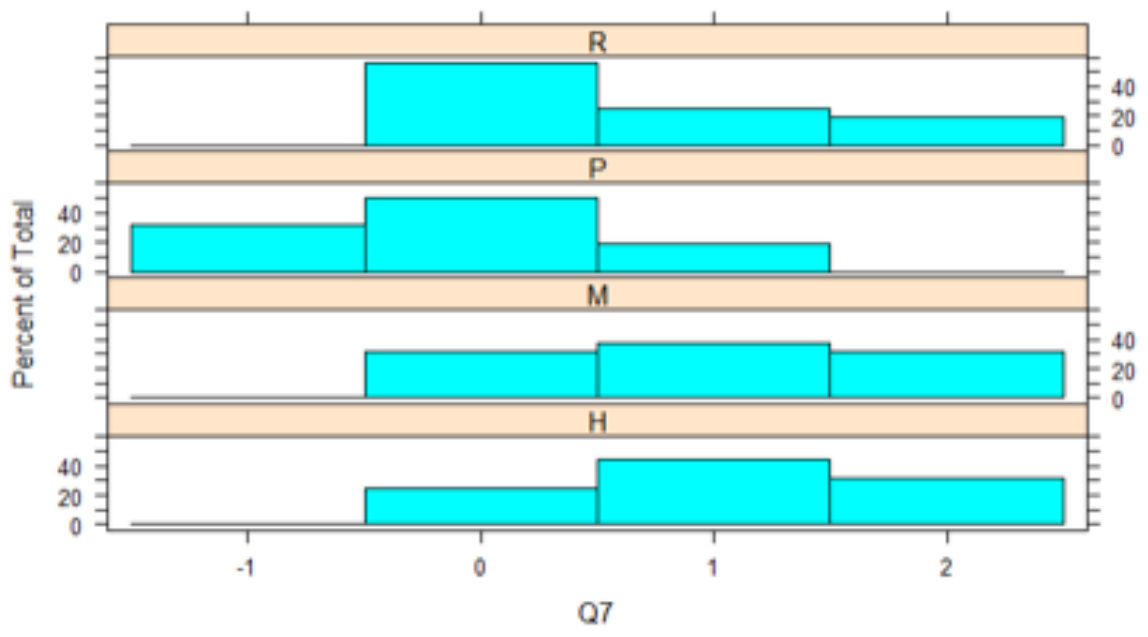

With responses to questions 1 and 7 being paired in their statistical output, this is indicative of the interpretation of hotel accommodations affecting mood enough to predict their likelihood of coming to that city again, as a traveler or guest. This is true whether they liked or did not like the accommodations. For example, the relatively poorer student mood associations with the Prague hotel (which was the hotel with the lowest star-rating of the four) predicted a similarly lower likelihood of coming to the city again. Future researchers should analyze a larger sample set of travelers. A similar study on retirees and their travel would be also interesting, as this demographic has different needs. Subsequent analysis may additionally focus on if responses may differ depending on if a traveler has a work versus leisure trip, and future SAs may examine if accommodations lower than a 2-star rating have a stronger negative impact on student moods. 


\section{REFERENCES}

[1] Barkley, A., \& Barkley, M. (2013, September). Long Term Knowledge from Short Term

[2] Study Abroad in Brazil and South Africa: Facilitating effective international experiences. NACTA Journal, 57(3a), p. 146-152.

[3] Becker, E. (2016). Overbooked: The exploding business of travel and tourism. New York, NY: Simon \& Schuster.

[4] Bosque, I., \& Martin, H. (2008). Tourist Satisfaction: a cognitive-affective model. Annals of Tourism Research, 35(2), 551-573.

[5] Cohen, E.(1985). The Tourist Guide: The origins, structure and dynamics of a role.Annals of Tourism Research, 12(1), 5-29.

[6] Chang, S., \& Gibson, H. (2011). Physically Active Leisure and Tourism Connection: Leisure involvement and choice of tourism activities among paddlers. Leisure Sciences: An interdisciplinary journal,33(2), 162-181.

[7] Chang, J. (2008). Tourists' Satisfaction Judgments: An investigation of emotion, equity, and attribution. Journal of Hospitality \& Tourism Research, 32(1), 108-134.

[8] Chang, W. (2014). A Study on the Key Success Factors of Service Quality for International Hotels. Acta Oeconomica, 64(2), 25-37.

[9] Chieffo, L., \& Griffiths, L. (2004, Fall). Large-scale assessment of student attitudes after a shortterm study abroad program. Frontiers Journal: The interdisciplinary journal of Study Abroad, 10, 165-177.

[10] College Factual. (2020). 2020 Hospitality Management Degree Guide. Retrieved from https://www.collegefactual.com/majors/business-management-marketing-sales/hospitalitymanagement/.

[11]Deloitte. (2019). 2019 US Travel and Hospitality Outlook. Retrieved from https://www2.deloitte.com/content/dam/Deloitte/us/Documents/consumer-business/us-consumer2019-us-travel-and-hospitality-outlook.pdf.

[12] Gao, Y., \& Mattila, A. (2016, July). The Impact of Option Popularity, Social Inclusion/Exclusion, and Self-affirmation on Consumers' Propensity to Choose Green Hotels. Journal of Business Ethics, 136(3), 575-585.

[13] Jones, P., \& Chen, M. (2011, January). Factors Determining Hotel Selection: Online behavior by leisure travelers. Tourism and Hospitality Research, 11(1), 83-95.

[14] Kendall College. (2018). Why is the Hospitality Industry Important? Retrieved from https://www.kendall.edu/blog/why-is-the-hospitality-industry-important/.

[15] Kozak, M., \& Kozak, N. (2015). Tourism Economics: A practical perspective. Berlin, GE: Cambridge Scholars Publishing.

[16] Ladhari, R. (2007). The Effect of Consumption Emotions on Satisfaction and Word-of-Mouth Communications. Psychology and Marketing, 24(12), 1085-1108. 
[17] Man-U, I. (2017). Understanding the Effects of Multi-Dimensional Tourism Experiences on Tourists' Positive Emotions and Satisfaction in the Context of Casino Hotels. International Journal of Culture, Tourism, and Hospitality Research, 11(2), 142-156.

[18] Matias, A., Nijkamp, P., \& Romao, J. (2016). Impact Assessment in Tourism Economics. New York, NY: Springer Publishing.

[19] Martinsen, R. (2011, March). Predicting Changes in Cultural Sensitivity among Students of

[20] Spanish during Short-term Study Abroad. Hispania, 94(1), 121-141.

[21] Maurer, C., \& Siller, H. (2019). ISCONTOUR 2019 Tourism Research Perspectives: Proceedings of the International Student Conference in Tourism Research. New York, NY: Books on Demand.

[22] Meng, S., \& Siriwardana, M. (2016). Assessing the Economic Impact of Tourism. A computable general equilibrium modelling approach. London, UK: Palgrave Macmillan Publishing.

[23] Mitas, O., Yarnal, C., Adams, R., \& Ram, N. (2012a). Taking a 'Peak' at Leisure Travelers' Positive Emotions. Leisure Sciences: An interdisciplinary journal, 34(2), 115-135.

[24] Nawijn, J. (2010). The Holiday Happiness Curve: A preliminary investigation into mood during a holiday abroad. International Journal of Tourism Research, 12(3), 281-90.

[25] Nawijin, J., Mitas, O., Lin, Y., \& Kerstetter, D. (2012, November 16). How Do We Feel on vacation? A closer look at how emotions change over the course of a trip. Journal of Travel Research, 52, 265.

[26] Pearce, P. (1981). 'Environment Shock': A study of tourists' reactions to two tropical islands. Journal of Applied Social Psychology, 11(3), 268-80.

[27] Singh, D., Birch, A., \& McDavid, H. (2006, September). Impact of the Hospitality-Tourism Sector on the Jamaican Economy, 1974-1993: An input-output approach. Social and Economic Studies, 55(3), 183-207.

[28] Slatten, T., \& Mehmetoglu, M. (2009). Atmospheric Experiences that Emotionally Touch Customers. Managing Service Quality,19(6), 721-746.

[29] Smith, O. (2018). The Countries that Rely Most on Your Money. The Telegraph.Retrieved from https://www.telegraph.co.uk/travel/maps-and-graphics/Mapped-The-countries-that-rely-most-onyour-money/.

[30] Su, L., \& Hsu, M. (2013b). Service Fairness, Consumption Emotions, Satisfaction, and Revisit Intentions: The experience of Chinese heritage tourists. Journal of Travel \& Tourism Marketing, 30(8), 786-805.

[31] Teichler, U., \& Steube, W. (1991, April). The Logics of Study Abroad Programs and Their Impacts. Higher Education and the Flow of Foreign Students, 21(3), 325-349.

[32] Tribe, J. (2011).The Economics of Recreation, Leisure, and Tourism. London, UK: Routledge Publishing.

[33] Tsai, S. (2010). Shopping Mall Management and Entertainment Experience: A cross-regional investigation. The Service Industries Journal, 30(3), 321-337.

[34] Vande Berg, M., Paige, R., \& Hemming, K. (2012). Student Learning Abroad: 
[35] What our students Are learning, what they're not, and what we can do about it. Sterling, VA: Stylus Publishing, LLC.

[36] Vanhove, N. (2011). The Economics of Tourism Destinations. London, UK: Elsevier Publishing.

[37] Voigt, C., Howat, G., \& Brown, G. (2010). Hedonic and Eudemonic Experiences Among Wellness Tourists: An exploratory enquiry. Annals of Leisure Research, 13(3), 541-562.

[38] Weiler, B., \& Davis, D. (1993). An Exploratory Investigation into the Roles of the Nature-based Tour Leader. Tourism Management, 14(2), 91-98.

[39] Wood, R. (2017). Hotel Accommodation Management. London, UK: Routledge Publishing.

[40] World Tourism Organization. (2020). International Tourism Highlights, 2019. Retrieved from https://www.e-unwto.org/doi/pdf/10.18111/9789284421152.

[41] World Travel and Tourism Council (WTTC). (2018). Retrieved from https://www.wttc.org/.

[42] Wynn, J. (2011). The Tour Guide: Walking and talking New York. Chicago, IL: University of Chicago Press.

\section{Appendix A.}

\section{Seven Questions}

1) How much did the accommodations affect your likelihood of coming to the city again?

2) How much did the accommodations affect your likelihood of living and/or working in this city in the future?

3) What amount of money that you would be willing to pay to upgrade your accommodations if you took a trip to this city in the future?

4) What amount of money that you would be willing to be given to downgrade your accommodations if you took a trip to this city in the future?

5) What amount of money that you would be willing to pay to upgrade your accommodations if you took a trip to this city for this trip?

6) What amount of money that you would be willing to be given to downgrade your accommodations if you took a trip for this trip?

7) How did the accommodations affect your mood in this city?

\section{Appendix B.}

\section{Hotel Survey}

Student number:

How much did the accommodations affect your likelihood of coming to the city again?

No difference 
More likely to visit

Much more likely to visit

Less likely to visit

Much less likely to visit

How much did the accommodations affect your likelihood ofliving and/or working in this city in the future?

No difference

More likely to visit

Much more likely to visit

Less likely to visit

Much less likely to visit

What amount of money that you would be willing to pay to upgrade your accommodations if you took a trip to this city in the future?

None

Less than $10 \%$ of a weekly paycheck

More than $10 \%$ of a weekly paycheck

More than $25 \%$ of a weekly paycheck

More than $50 \%$ of a weekly paycheck

What amount of money that you would be willing to be given to downgrade your accommodations if you took a trip to this city in the future?

None

Less than $10 \%$ of a weekly paycheck

More than $10 \%$ of a weekly paycheck

More than $25 \%$ of a weekly paycheck

More than $50 \%$ of a weekly paycheck

What amount of money that you would be willing to pay to upgrade your accommodations if you took a trip to this city for this trip?

None

Less than $10 \%$ of a weekly paycheck

More than $10 \%$ of a weekly paycheck

More than $25 \%$ of a weekly paycheck

More than $50 \%$ of a weekly paycheck

What amount of money that you would be willing to be given to downgrade your accommodations if you took a trip for this trip?

None

Less than $10 \%$ of a weekly paycheck

More than $10 \%$ of a weekly paycheck

More than $25 \%$ of a weekly paycheck

More than $50 \%$ of a weekly paycheck 
International Journal of Education (IJE) Vol.8, No.2, June 2020

How did the accommodations affect your mood in this city?

No difference

More happy

Much more happy

Less happy

Much less happy

Appendix C.

\section{Visual Representations of Survey Results}

Munich

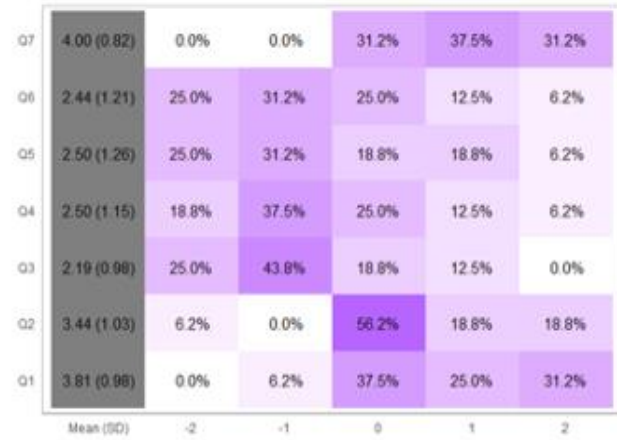

\section{For H}

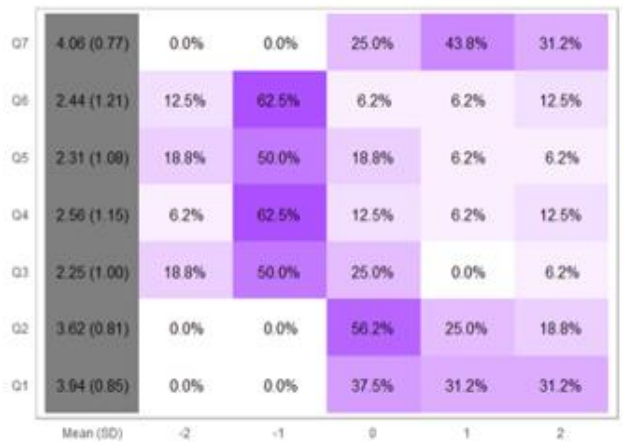

\section{Prague}

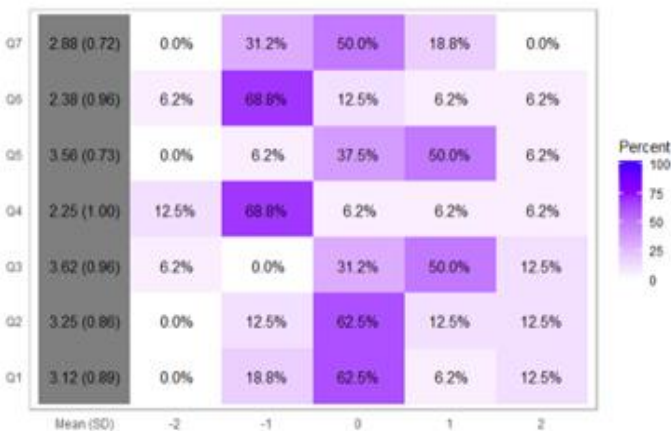

\section{For R}

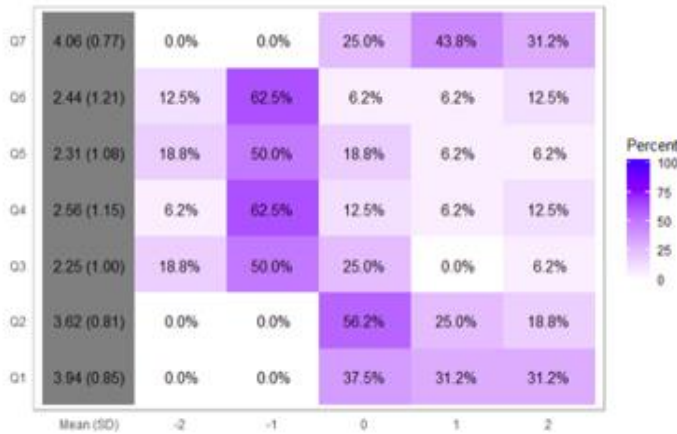

